\title{
Congenital Enteropathy and Intestinal Transplantation
}

\author{
Olivier Goulet
}

Reference Center for Rare Digestive Diseases, Department of Pediatric Gastroenterology-Hepatology and Nutrition, Hôpital Necker - Enfants Malades, Paris, France

\section{Key Words}

Intestinal failure $\cdot$ Citrulline $\cdot$ Congenital enteropathy $\cdot$

Parenteral nutrition $\cdot$ Liver disease $\cdot$ Intestinal

transplantation $\cdot$ Liver transplantation $\cdot$ Home

parenteral nutrition

\begin{abstract}
Intestinal failure (IF) requires the use of parenteral nutrition (PN). Causes of severe protracted IF include short bowel syndrome, severe motility disorders (total or subtotal aganglionosis or chronic intestinal pseudo-obstruction syndrome) and congenital diseases of enterocyte development. Severe liver disease may develop in patients with IF as a consequence of both underlying digestive disease and unadapted PN. Catheter-related sepsis and/or extensive vascular thrombosis may impede the continuation of safe and efficient PN. Thus management of patients with IF requires early recognition of the condition and the analysis of its risk of irreversibility. Timing of referral for intestinal transplantation remains a crucial issue. As a consequence, management should include therapies adapted to each stage of IF based on a multidisciplinary approach in centers involving pediatric gastroenterology, PN expertise, home-PN program, pediatric surgery, liver-intestinal transplantation program.
\end{abstract}

Copyright (C) 2006 Nestec Ltd., Vevey/S. Karger AG, Basel

\section{KARGER}

Fax +4161306 1234 E-Mailkarger@karger.ch www.karger.com
(C) 2006 Nestec Ltd., Vevey/S. Karger AG, Basel 0517-8606/06/0641-0025\$23.50/0

Accessible online at:

www.karger.com/ane
Intestinal failure (IF) is a condition of severe intestinal malabsorption requiring parenteral nutrition (PN). Congenital enteropathies that impair the intestinal mucosa lead to irreversible IF. The risk of complications of permanent $\mathrm{PN}$ is high, thus raising the possible need of intestinal transplantation (ITx).

\section{Definition of Intestinal Failure}

'Intestinal failure' is defined as the critical reduction of functional gut mass below the minimal amount necessary for adequate digestion and absorption to satisfy body nutrient and fluid requirements for health maintenance in adults or growth in children. However, this definition is not accepted uniformly. Some suggest that IF is better defined in terms of fecal energy losses rather than residual bowel length in patients with short bowel syndrome [1]. Another approach is to evaluate the degree of IF according to the amount of PN required for maintenance in adults and growth in children. Beside anatomic and nutritional criteria for defining IF, a biological marker of gut functional mass has been proposed recently [2]. Citrulline is a nonessential amino acid that is produced mostly by enterocytes [3]. Plasma citrulline levels may be measured easily reflecting the loss of functional mass in patients with short bowel syndrome (SBS) and in patients 
with various degrees of villous atrophy or experiencing intestinal graft rejection with villous atrophy [4]. In a recent study involving short bowel syndrome pediatric patients treated with recombinant human growth hormone, plasma citrulline levels increased significantly following treatment [5]. The current criteria for defining IF remain the inability to preserve growth in children without permanent dependence on PN.

\section{Causes of Intestinal Failure}

The natural history of IF in children is variable and influenced largely by the underlying disorder responsible for the loss of intestinal function. The most common type of IF is secondary to gastrointestinal infection. However, children with such acute IF are expected to recover completely with appropriate treatment. Nonetheless, post-enteritis protracted diarrhea remains a leading cause of IF in developing countries [6]. In developed countries, IF is dominated by congenital or early onset of severe and permanent disease requiring protracted or indefinite PN. Historically, SBS was one of the first recognized causes of protracted IF [7]. However, with the increasing and successful use of long-term PN during the last three decades, several other causes of IF emerged, e.g. severe extensive motility disorders including subtotal aganglionosis, chronic intestinal pseudo-obstruction syndrome and congenital diseases of enterocyte development [8].

\section{Congenital Enteropathy Causing Intestinal Failure}

An attempt to classify intractable diarrhea of infancy (IDI) with the degree of villous atrophy was proposed on the basis of immunohistological criteria that emphasize the role of activated $\mathrm{T}$ cells in the intestinal mucosa [9]. A multicenter survey from ESPGHAN collected cases of IDI and villous atrophy with precisely defined light microscopic characteristics that allowed the categorization of several types of IDI [10]. The first one was characterized by a mononuclear cell infiltration of the lamina propria and considered to be associated with activated $\mathrm{T}$ cells. The second histological pattern included early onset of severe diarrhea with villous atrophy without mononuclear cell infiltration of the lamina propria and specific histological abnormalities involving the epithelium. To date, several types of primary epithelial abnormalities in- ducing IDI have been identified. The first described was microvillous atrophy (MVA) or microvillous inclusion disease and more recently tufting enteropathy or intestinal epithelial dysplasia (IED) [11]. Some small for gestational age patients present with phenotypic abnormalities that correspond to IDI [12].

\section{Microvillous Atrophy}

In 1978, Davidson et al. [13] reported 5 infants with severe, persistent diarrhea beginning in the newborn period, in whom light microscopy revealed crypt hypoplastic villous atrophy. Electron microscopic examination of small intestinal biopsies from 3 of the patients showed severe brush border abnormalities and increased liposome-like bodies, and in 1, intracytoplasmic cysts with a brush border architecture. Children were also reported with characteristic cytoplasmic inclusions of the brush border membrane [14]. From these clinical and histological descriptions, MVA was established as a distinct disease within the syndrome of IDI. In its typical form MVA is a congenital disorder of intestinal epithelial cells that presents initially as neonatal intractable diarrhea [14].

\section{Clinical Expression}

In general, infants develop severe watery diarrhea within the first days after birth. Stool volumes may be as high as $250-300 \mathrm{ml} / \mathrm{kg}$ body weight/day and fecal electrolyte concentrations are similar to those of the small intestinal fluid. This disorder is particularly life-threatening since massive diarrhea leads to rapid dehydration, electrolyte imbalances, and subsequent metabolic decompensation within a few hours. Severe watery diarrhea persists despite bowel rest. Differential diagnoses may include congenital chloride diarrhea and sodium malabsorption diarrhea that can be distinguished easily from MVA by assessment of blood and stool electrolytes [15-16]. In contrast, the clinical presentation of MVA also may be very atypical with a full and distended small bowel and colon mimicking a pseudo-occlusion sydrome. The most common onset of diarrhea in MVA is within the first few days (early-onset or congenital form). However, in a few patients onset of diarrhea may be delayed (first month) and less severe (late-onset form).

Histopathological Analyses

Diagnosis may be made easily from a light microscopic examination of a duodenal or jejunal biopsy specimens. On hematoxylin-eosin staining, the mucosa appears flattened with hypoplastic villous atrophy. Highly character- 
Fig. 1. Periodic acid-Schiff (PAS) staining. A Normal mucosa, normal PAS, brush border staining. B Abnormal accumulation of PAS, positive material in the apical cytoplasm of epithelial cells in microvillous inclusion disease.
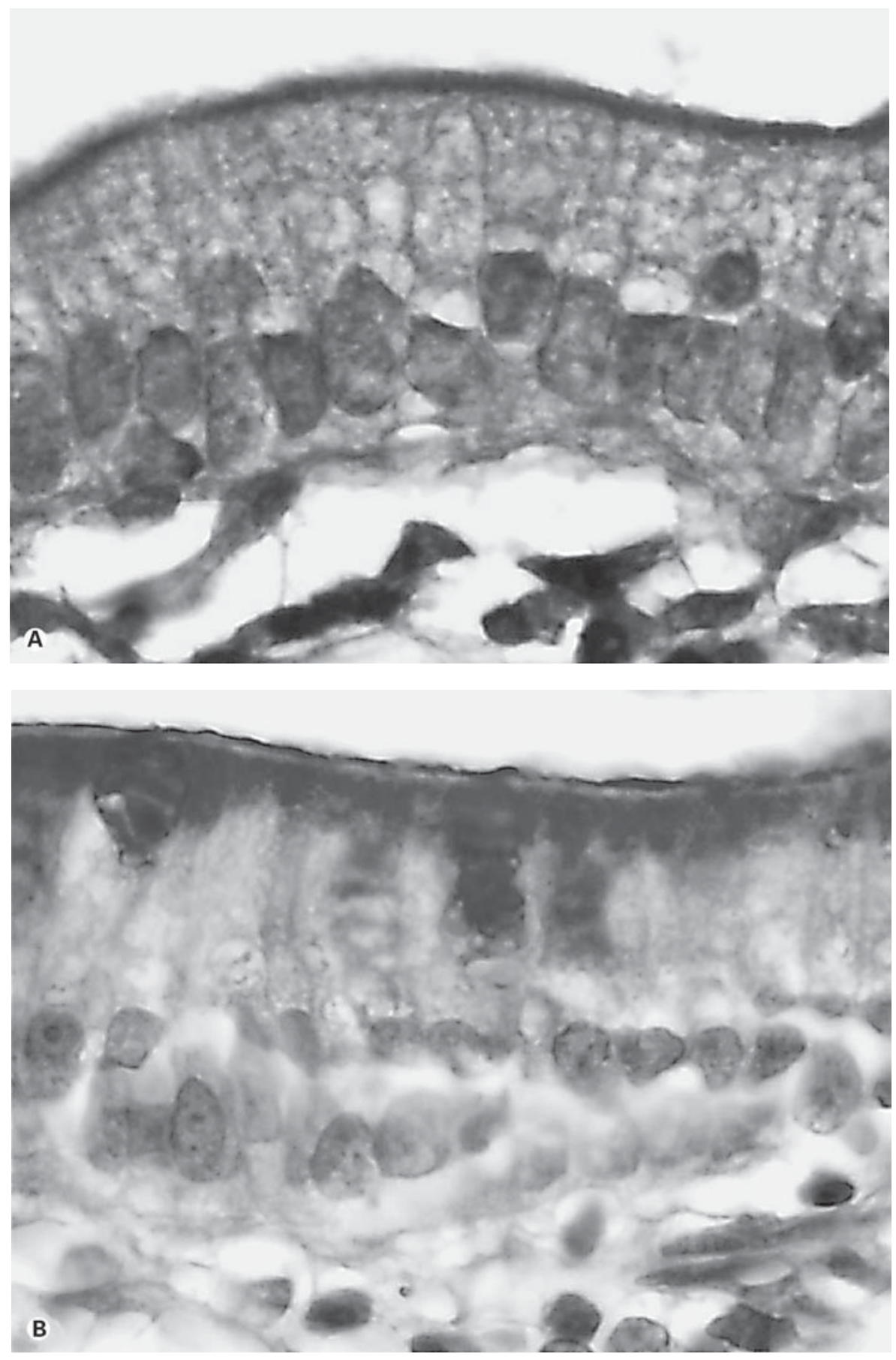
Fig. 2. Microvillous inclusion disease. Electron microscopy of a jejunal biopsy specimen. The brush border is almost absent. The cytoplasm contains a microvillous inclusion.

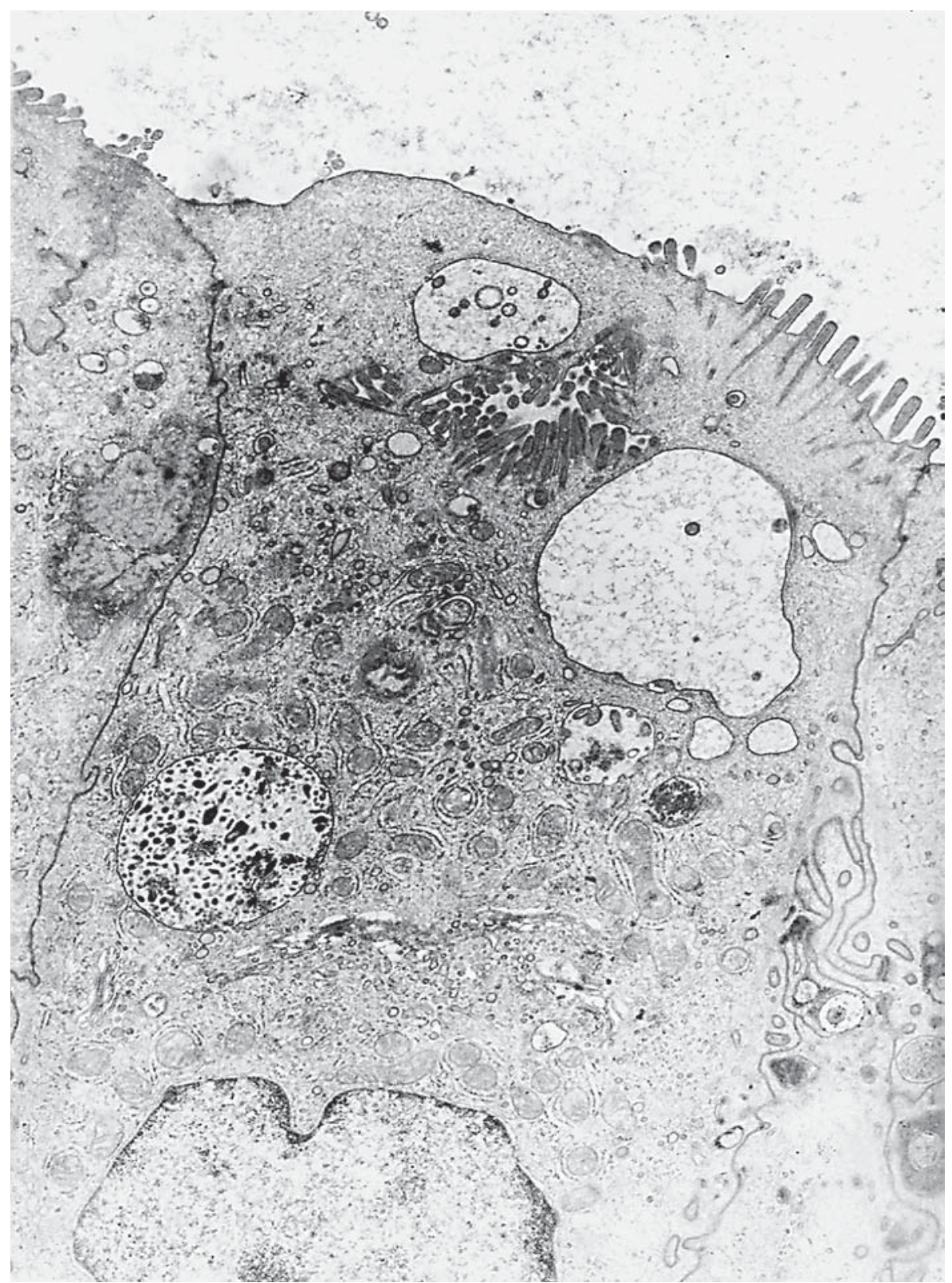

istic for this disorder is the accumulation of periodic acidSchiff (PAS)-positive secretory granules within the apical cytoplasm of enterocytes $[17,18]$ (fig. 1). On the ultrastructural level, rare or absent microvilli and cytoplasm inclusions of microvilli of enterocytes are seen. These anatomical changes define this entity [19]. A new valuable tool for the light microscopic diagnosis of MVA was proposed recently [20,21]. CD-10 is a membrane-associated neutral peptidase, shown to have a linear brush border staining pattern in the normal small intestine. In contrast to this surface staining in different conditions (normal intestine, celiac disease, autoimmune enteropathy, and allergy), all MVA cases demonstrate prominent intracytoplasmic CD-10 immunoreactivity in surface enterocytes [20]. Similar results were obtained with PAS, polyclonal carcinoembryonic antigen and alkaline phosphatase, three stains known to show cytoplasmic staining of surface enterocytes in MVA [22]. On electron microscopy, surface epithelial cells show absent or grossly abnormal microvilli, and numerous vesicular bodies of various 
sizes, and characteristic microvillous inclusions (fig. 2). Crypt cells are morphologically almost normal. They do not contain increased numbers of apical vesicles and vesicular bodies. Microvillous inclusions and increased secretory granules are also present in the large bowel epithelium. This is particularly important because this tissue is more easily accessible for biopsy, especially in early infancy.

Pathophysiology and Mode of Transmission

A defect in the membrane trafficking of immature and/ or differentiating enterocytes also was discussed as an etiopathogenic mechanism in MVA [19, 22]. A direct functional consequence of this membrane defect is complete IF. It has been speculated that this disease is associated with a disorder of the enterocyte cytoskeleton. The cytoskeleton produces an abnormal assembly of microvilli. Intestinal microvillous dystrophy was reported to be a hypothetic variant of MVA [22]. The underlying pathogenesis of MVA, however, remains unclear. When analyzing the turnover of sucrase-isomaltase, as a representative brush border protein, there is clear evidence that direct and indirect constitutive pathways are intact in MVA [19]. Since in both congenital and late onset MVA, microvilli appear to be near normal in regions where secretory granules first accumulate, a defect in microvillous biosynthesis is not likely to be the basis of the disease. Recently, by investigating the secretory granules, Phillips et al. [23] suggested that MVA involves a defect in the exocytosis of the glycocalyx that might impair normal cell functions.

Considering the number of cases with affected siblings and the frequency of consanguinity among patients, this disease appears to be transmitted as an autosomal recessive trait [24]. To date no candidate gene has been identified, but MVA was reported in a girl with autosomal dominant hypochondroplasia [25]. The gene defect of this hypochondroplasia was localized recently to chromosome region $4 \mathrm{p} 16.3$. This might help to elucidate the genetic basis of MVAs.

\section{Long-Term Outcome}

The largest multicenter survey of 23 MVA patients [14] revealed an extremely reduced life expectance, with a 1-year survival rate of less than 25\%. Most children died of septic complications, liver failure or metabolic decompensation. Few cases of MVA, especially the lateonset form, and those with limited stool outputs may survive with only partial PN. Treatment with corticosteroids, colostrum or epidermal growth factor has not been successful, but octreotide was used with partial success in 1 patient [14]. Contrary to the initial outcome before the 1980s, PN now allows most infants and children to survive. However, complications related to inadequate PN limit long-term survival. In addition, without evidence of an associated renal disease, some of these infants and children present with chronic hydro-electrolytic imbalances and acidosis with subsequent impaired growth. Some others, because of repeated dehydration episodes associated with inappropriate phosphocalcic intakes, present with nephrocalcinosis. Finally, even with adequate long-term PN and normal growth, high and uncomfortable stool outputs persist and often require daily fluid and electrolyte replacements with the high risk of severe dehydration. Thus, ITx may be the only definitive treatment for this rare intestinal disease.

Several cases of successful transplantation for MVA were reported [26-29]. Transplantation involved isolated intestine [26] or combined transplants with the liver $[27,28]$. Whether or not the colon should be transplanted with the small bowel remains controversial. We recently reported patients with early-onset congenital MVA [29]. Two patients died before they could be put on a waiting list for small bowel transplantation, 1 patient is still awaiting small bowel transplantation. We have performed cadaveric ITx in 7 patients aged between 3 and 11 years using tacrolimus, steroids and IL-2 blockers. Three ITx were performed and 4 associated with the liver. Right colon transplantation was performed in 5 cases ( 2 isolated ITx). Six patients $(86 \%)$ have survived with a median follow-up of 3 (range 1-8) years. Complete weaning from PN was achieved in all patients. For the first time ITx alone or in combination with the liver offered MVA children a long-term perspective $[29,30]$.

\section{Intestinal Epithelial Dysplasia or Tufting \\ Enteropathy}

Three cases of neonatal severe diarrhea with abnormal epithelial pictures were reported by Reifen et al. [31] under the name 'tufting enteropathy'. We identified 9 cases of severe neonatal diarrhea which were clearly different from MVA [11]. Further studies in these patients showed that intestinal epithelial dysplasia (IED) is a constitutive epithelial disorder involving both the small intestine and colon [32]. In our experience IED seems frequent in patients of Arabic origin, and in the Middle-East and North Africa. A main characteristic of this disease is its clinical and histological heterogeneity and its association with malformations or other epithelial diseases. 
Fig. 3. Intestinal epithelial dysplasia. Partial villous atrophy with crypt hyperplasia and/or pseudocystic crypt appearance, branching pictures and disorganization of surface epithelium.

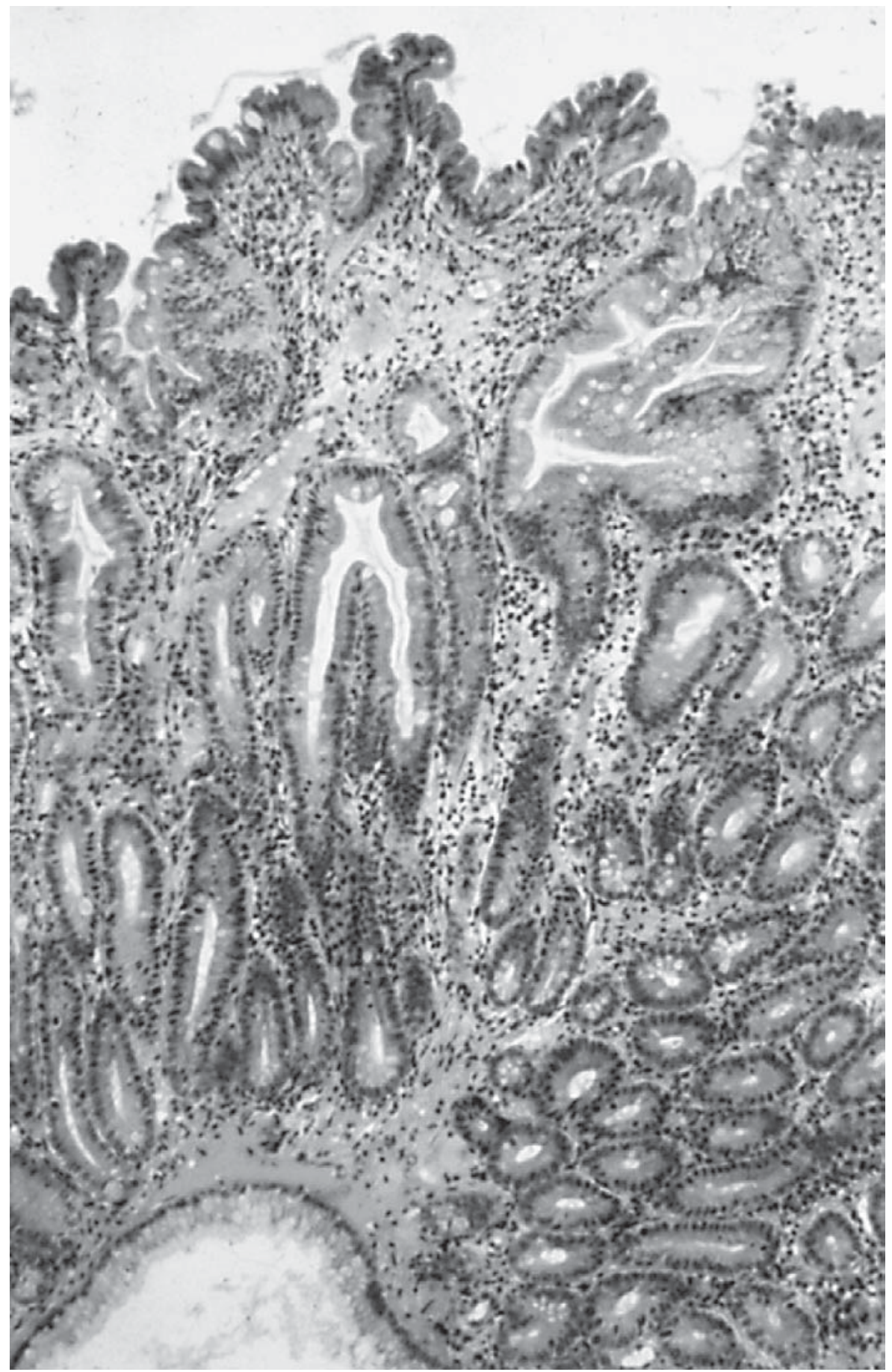


Clinical Expression

Typically, patients present during the first weeks of life with severe diarrhea. Most have consanguineous parents and/or an affected sibling. Some affected family members died during the first months of life with severe diarrhea of unknown origin. Most of the time, diarrhea persisted despite bowel rest but mortality was less than that observed with MVA. Attempts to use continuous enteral feeding with a protein hydrolysate or amino acids worsened diarrhea. Newborns rapidly fail to thrive and develop severe protein energy malnutrition.

\section{Histological Presentation}

Villous atrophy is present but variable in severity. In its typical form, abnormalities are localized mainly to the epithelium and include a disorganization of surface enterocytes with focal crowding resembling tufts (fig. 3). These characteristic 'tufts' of extruding epithelium, first described by Reifen et al. [31], are seen towards the villous tip, and may affect up to $70 \%$ of the villi. The tufting process is not limited to the small intestine but also involves the colonic mucosa [11]. This picture also can be observed in the crypt epithelium and, in addition, crypts often have an abnormal aspect with dilatation such as pseudocysts and abnormal regeneration with branching [11]. Study of the basement membrane components demonstrated abnormal laminin and heparan sulfate proteoglycan deposition at that level compared to biopsy specimens from patients with celiac disease or autoimmune enteropathy [11]. Relative to controls, there was faint and irregular laminin deposition at the epithelial lamina propria interface while heparan sulfate proteoglycan deposits were large and lamellar suggestive of the abnormal development of the basement membrane. These may be the origin of the epithelial abnormalities. On the other hand, we observed an increased immunohistochemical expression of desmoglein in IED, and ultrastructural changes in desmosomes that were increased in length and number [32] (fig. 4).

IED is suspected most often after elimination of MVA on PAS stained slides. Its final diagnosis is made after repeated intestinal biopsies which change from subnormal in early life (only nonspecific villous atrophy with or without monocellular cell infiltration of the lamina propria) to the characteristic tufts. Another difficulty is related to the infiltration of the lamina propria by $\mathrm{T}$ cells. $\mathrm{T}$ cell infiltrates support the diagnosis of an immune-related enteropathy, as previously described especially when tufts are missing. One can speculate that defective cell adhesion increases intestinal permeability with a subsequent inflammatory reaction. Murch et al. [33] described this type of lesion in infants with epithelial dysplasia.

\section{Associated Disorders}

Several cases of IED were reported as being associated with specific phenotypic abnormalities, e.g. Dubowitz syndrome or malformation syndrome [34, 35]. An association between congenital IDI and choanal atresia was reported recently in 4 children [34]. We have observed malformations including rectal or esophageal atresia and recently reported a nonspecific punctiform keratitis involving about $60 \%$ of patients [36]. This keratitis is very intriguing since it is also an epithelial disease that might help to elucidate the molecular mechanisms of intestinal epithelial disease. The fact that some children have no ophthalmologic symptoms illustrates the likely heterogeneity of the disease.

Interestingly, Lachaux et al. [37] recently reported the case of a newborn presenting with pyloric atresia and intractable diarrhea. Light microscopic examination showed extensive desquamation from the fundus to the rectum with only a few epithelial cells remaining at the crypt bases. Electron microscopy of the gut epithelium revealed normal desmosomes but a cleavage located between the lamina propria and the basal pole of the enterocytes. This initial description was related to a congenital deficiency of the $\alpha 6 \beta 4$ integrin known to be defective in epidermolysis bullosa.

Pathophysiology and Mode of Transmission

IED was shown to be associated with an abnormal basement membrane compared to those from biopsy specimens from patients with celiac disease or autoimmune enteropathy [11]. Basement membrane molecules are involved in epithelial mesenchymal cell interactions, which are instrumental in intestinal development and differentiation [38]. Alterations suggestive of abnormal cell-cell and cell-matrix interactions were seen in patients with IED without any evidence for abnormalities in epithelial cell polarization and proliferation [32]. Alterations included an abnormal distribution of adhesion molecules, the $\alpha 2 \beta 1$ integrin along the cryptvillous axis. The $\alpha 2 \beta 1$ integrin is involved in the interaction of epithelial cells with various basement membrane components, such as laminin and collagen. Pathophysiological mechanisms resulting in an increased immunohistochemical expression of desmoglein, and the ultrastructural changes in desmosomes remain unclear [32]. A mouse with a loss of function change in the 


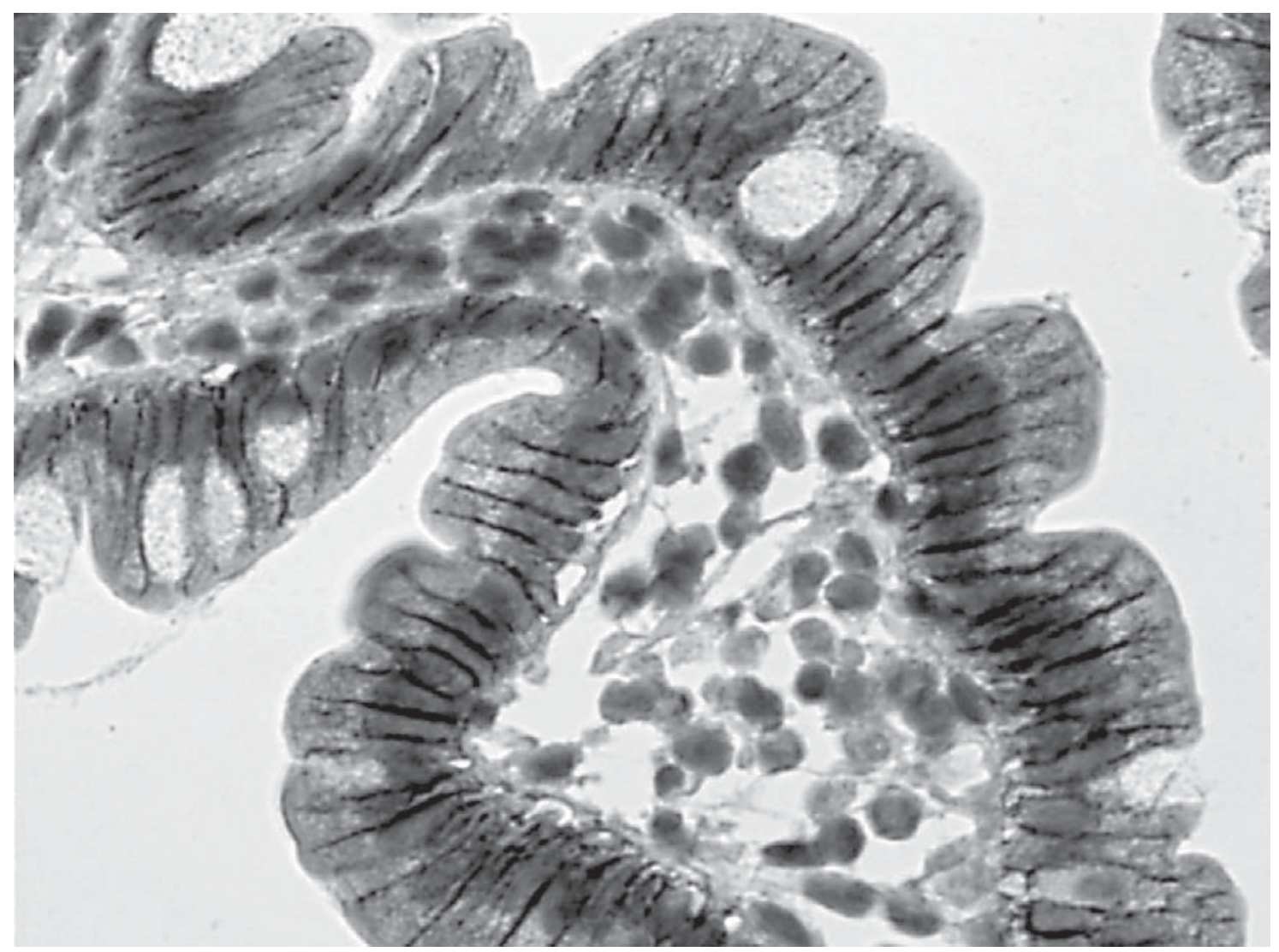

Fig. 4. Intestinal epithelial dysplasia. Increased expression of desmoglein staining of the tight junction in a patient with intestinal epithelial dysplasia.

gene encoding the transcription factor Elf3 has morphologic features resembling epithelial dysplasia in infants [39]. In this mouse model, there is abnormal morphogenesis of the villi and progenitor crypt cells appear normal. The enterocytes in Elf3-deficient mice produce low levels of the transforming growth factor- $\beta$ type- 2 receptor that induces the differentiation of immature intestinal epithelia. Currently, in human infants, the primary or secondary nature of the observed modifications remains to be determined. The presence of tufts may provide important clues. Tufts correspond to nonapoptotic epithelial cells at the villous tips that are no longer in contact with the basement membrane. Although speculative, a defect in normal enterocyte apoptosis at the end of their lifespan or an altered cell-cell contact may be responsible for this effect. The primary or secondary nature of the formation of tufts remains to be determined.
To date the genetic origin of this disorder is suspected from the clear association of parental consanguinity and/or affected siblings. These features suggest an autosomal recessive transmission. The gene involved in this congenital inherited autosomal recessive disease is not yet identified. This enteropathy appears more common than MVA, especially in the Middle-East population.

\section{Outcome}

Neonatal diarrhea that resists all treatments requires permanent PN. However, it seems that some infants develop milder phenotype than others [40]. Because of partial residual intestinal function and the limited amount of stool output, some patients need only partial long-term PN with 3-4 times weekly infusions. However, careful monitoring should be performed to avoid progressive growth retardation. In most patients, the severity of in- 
testinal malabsorption and diarrhea makes them totally dependent on daily long-term PN with a subsequent risk of complications. IED can be another indication for ITx $[41,42]$.

\section{Other Congenital Enteropathies}

The so-called 'phenotypic diarrhea', which is an IDI syndrome associated with phenotypic abnormalities and immune deficiency, also is a rare, recently reported disease [12]. Affected patients present with diarrhea within the first 6 months of life ( $<1$ month in most cases) and share several clinical features. They are small for gestational age and have an abnormal phenotype [12]. All have facial dysmorphism with prominent foreheads, broad noses and hypertelorism. They have a distinct hair abnormality, tricorrhexis nodosa, in which the hair is woolly, difficult to manage, easily pulled out and poorly pigmented. These features also are seen in children of Middle-East origin. Among the congenital forms of hair dysplasia, trichorrhexis nodosa is very common and can be present in several pathologic conditions [43, 44]. These patients also have defective antibody responses despite normal serum immunoglobulin levels, and defective antigen-specific skin tests despite positive proliferative responses in vitro [12]. Small bowel biopsy specimens of patients with syndromatic diarrhea show moderate or severe villous atrophy with inconstant mononuclear cell infiltrates of the lamina propria and the absence of epithelial abnormalities. Histologically, there are no specific abnormalities. The prognosis of this type of IDI is poor since most patients die between the ages of 2 and 5 years. Some suffer the early onset of liver disease [12]. The cause of this diarrhea is unknown and the relationships among low birth weight, dysmorphism, severe diarrhea, trichorrhexis and immune deficiency are unclear.

\section{Management of Intestinal Failure}

\section{Long-Term Parenteral Nutrition}

Whether in hospital or at home, long-term PN exposes the patient to several complications including catheterrelated sepsis and thrombosis, liver and bone disease [45]. Daily catheter care and prevention of septic complications are essential [46]. Liver function tests should be performed on a regular basis because of the risk of cholestasis and liver injury. Ultrasonography aiming to look for sludge or cholelithiasis should be repeated at least twice a year in patients with gall bladders. In addition, bone mineralization should be examined using DEXA, phosphorus and calcium status should be assessed, and diets should be managed to prevent $\mathrm{PN}$-related bone disease.

\section{Factors and Management of Liver Disease}

Liver disease is the most frequent and the most severe complication in IF patients. The expression 'PNrelated liver disease' should be replaced by 'IF-related liver disease'. Indeed, the most important factors inducing cholestasis and end-stage liver disease are related to impaired intestinal function and bacterial overgrowth. Liver injury is aggravated further by inadequate PN.

The main factors related to liver disease may be listed as follows:

(1) Disruption of the enterohepatic cycle (ileal disease or resection) $[47,48]$

(2) Intestinal stasis with subsequent intraluminal bacterial overgrowth and/or translocation (endotoxinemia) [49]

(3) Recurrent catheter-related sepsis [50, 51]

(4) Prematurity [51]

(5) Inadequate macronutrient intake such as continuous PN infusion with excessive glucose intake leading to hyperinsulinism and subsequent steatosis [52] and inadequate amino acid supply [49]

(6) Excessive intake of long-chain polyunsaturated fatty acids with subsequent lipoperoxidation $[53,54]$ and high content of phytosterols from soybean oil-based emulsions [55]

(7) Aluminum, iron and/or chromium overloads [5658]

Premature and/or small for gestational age infants with severe necrotizing enterocolitis are at especially high risk of developing liver disease and early end-stage liver failure because of the combination of prematurity, subocclusion, Gram-negative sepsis, protracted bowel rest, continuous instead of cyclic PN infusion, and repeated catheter-related sepsis.

Prevention or resolution of liver injury may be possible by:

(1) Stimulating enterobiliary axis by ensuring the ingestion of long-chain triglycerides or breast milk, or by injection of cholecystokinin analogs [59]

(2) Suppressing the intraluminal bacterial overgrowth caused by intestinal stasis by giving metronidazole [60] and/or performing tapering enteroplasty

(3) Using ursodesoxycholic acid (30 mg/ $\mathrm{kg} /$ day) to decrease liver injury [61] 
(4) Avoiding catheter-related sepsis by appropriate daily care of the line [50, 51]

(5) Adapting PN intake by:

(a) Limiting glucose intake to reduce hepatic fat accumulation [62, 63], and

(b) Using the appropriate type and amount of intravenous fat emulsion to provide essential fatty acids, reducing glucose load and limiting peroxidation [53-55]. The recent development of olive oil-based fat emulsions may reduce peroxidation [54]. The daily administration of intravenous lipid should not exceed $2-2.5 \mathrm{~g} / \mathrm{kg}$

(6) Controlling the lipid supply and rate of delivery and/or stopping intravenous lipids as soon as thrombocytopenia, hyperbilirubinemia and/or jaundice appear [53]

(7) Using new pediatric adapted amino acid solutions that provide appropriate amino acids plus taurine [49]

(8) Performing cyclic PN that reduces hyperinsulinism and liver steatosis [64]

(9) Adapting iron intake and decreasing the aluminum content of the PN solutions [65]

With appropriate care and prevention, liver disease may be delayed or even avoided and the patient may be maintained in a nutritional and general condition offering better prognosis when isolated small bowel transplantation is required for irreversible IF.

\section{Intestinal Transplantation}

Whatever the cause of protracted or irreversible IF, long-term $\mathrm{PN}$ is the mainstay of therapy. Home PN allows infants and children to grow in the best psychological environment $[66,67]$. The irreversibility of IF has to be demonstrated before ITx is considered.

When ITx becomes the indicated therapeutic option, extensive multidisciplinary discussions among transplant surgeons and pediatric gastroenterologists are mandatory. Assessments and decisions are based on the occurrence of complications listed during the workshop held at the International Symposium on Small Bowel Transplantation in Miami, September 2003. These criteria are similar to those reported in the position paper of the American Society of Transplantation [68] and continue to be debated, especially those that relate to vascular thrombosis and sepsis:

(1) Liver disease (bilirubin levels $>3 \mathrm{mg} / \mathrm{dl}$, splenomegaly, thrombocytopenia, gastroesophageal varices, coagulopathy, stomal bleeding, hepatic fibrosis, or cirrhosis)
(2) Thrombosis of major venous accesses ( $>2$ thromboses in subclavian, jugular, or femoral veins). In our practice 1 access left in the superior vena cava bed

(3) Recurrent catheter-related sepsis (2 episodes of systemic sepsis secondary to line infection per year, 1 episode of line-related fungemia, septic shock, or acute respiratory distress syndrome)

(4) Underlying disease causing uncontrollable water electrolyte losses and frequent severe acute dehydration

These criteria are guidelines, not formal recommendations. They must be balanced with the risks of ITx.

Contraindications to ITx do not differ from those pertaining to other solid organs. Due to the risks of ITx, especially in cases of poor recipient conditions at the time of transplantation and the donor pool size, the concept that the patient must have the potential to derive an obvious benefit from the procedure must remain paramount.

Other contraindications include congenital or acquired neurological disabilities, life-threatening extra-digestive illnesses, congenital or acquired immune disorders, non-resectable malignancy, and insufficient vascular patency to guarantee easy central venous access for up to 6 months after ITx.

\section{Type of Transplantation}

Patients with irreversible IF and end-stage liver disease (liver cirrhosis) are clearly candidates for life-saving procedures such as combined liver-small bowel transplantation (LITx). Patients with severe hepatic fibrosis are more difficult to manage. Repeated liver biopsies within 6-12 months and careful assessments of portal hypertension are necessary. In addition, it is difficult to assess the amount of functional liver tissue necessary to withstand the insult of portal diversion during the transplantation procedure. Children with severe advanced and progressive hepatic fibrosis are usually candidates for LITx. However, some PN-dependent patients with advanced liver dysfunction may experience functional and biochemical liver recovery that occurs parallel to autologous gut salvage. Several consecutive cases of severe cholestasis recovered totally after discontinuation of intravenous lipid administration [69]. Histology is not always predictive of functional liver recovery [70]. Once cirrhosis has been established, however, survival at 1 year is only $20-30 \%$ [71].

\section{Timing of Referral for Intestinal Transplantation}

Factors impacting the survival of children with IF referred for ITx are well known including: age $<1$ year; surgical disease; bridging fibrosis or cirrhosis; bilirubin levels 
$>3 \mathrm{mg} / \mathrm{dl}$, and thrombocytopenia [71]. It is well established that patients referred to intensive care centers for LITx are debilitated, have multiple complications and prolonged stays. The UNOS report indicates that mortality of patients on ITx waiting lists is higher than on other transplantation waiting lists [72]. It may explain the low patient and graft survival rates reported in various studies [73]. The Intestinal Transplant Registry confirmed that transplantations performed in patients waiting at home versus waiting in hospital have a better 1-year survival (74 vs. $59 \%$; $<<0.00001$ ) [73]. The trend to transplant proportionately more patients who are waiting at home was a major factor contributing to the recently improved graft and patient survival rates [73].

Few centers manage all the stages of IF from onset to ITx, including the home PN program. A marked discrepancy was reported in clinical status between children referred for ITx from centers with and without nutritional care teams [74]. Long-term management of IF has become a very important concern as suggested by recently published studies [75]. A national or international network might provide data on IF on which the needs for health care should be based [76] and make it possible to optimize management, upgrade the medical approach and to promote basic and applied research in the field.
Indeed, appropriate management of IF requires reference centers using therapeutic strategies that are based on a multidisciplinary approach that involves pediatric gastroenterologists, nutritionists, pediatric surgeons, specialized nurses, dieticians, social workers and psychologists. This integrated approach should be adapted to each type and stage of IF including home PN and a transplantation program.

\section{Conclusion}

Early management of IF in reference centers by a multidisciplinary group is the key to the timely recognition of IF and its reversal, improved outcomes, and timely ITx. As recently stressed by a Working Group report of Pediatric Gastroenterology and Nutrition, research is needed in all fields of adaptation after small bowel resection and to identify the genes involved in congenital enteropathy or intestinal pseudo-obstruction syndrome [77]. It is also mandatory to assess the respective costs of long-term home PN and ITx and target the best option for maximizing the quality of life of affected children and their families.

\section{References}

1 Nordgarrd I, Hansen BS, Mortensen PB: Importance of colonic support for energy absorption as small-bowel failure proceeds. Am J Clin Nutr 1996;64:222-231.

$\checkmark 2$ Crenn $\mathrm{P}$, Coudray-Lucas $\mathrm{C}$, Thuillier F, Cynober L, Messing B: Postabsorptive plasma citrulline concentration is a marker of absorptive enterocyte mass and intestinal failure in humans. Gastroenterology 2000;119:14961505.

-3 Crenn P, Vahedi K, Lavergne-Slove A, Cynober L, Matuchansky C, Messing B: Plasma citrulline: A marker of enterocyte mass in villous atrophy-associated small bowel disease. Gastroenterology 2003;124:1210-1219.

4 Pappas PA, Saudubray JM, Tzakis AG, et al: Serum citrulline and rejection in small bowel transplantation: a preliminary report. Transplantation 2001;72:1212-1216.

5 Dabbas-Tyan M, Colomb V, Rosilio M, Landais P, Ricour C, Goulet O: Evaluation of the effect of recombinant human growth hormone (rhGH) treatment of children with short bowel syndrome. J Pediatr Gastroenterol Nutr 2000; 31:S165-S166.
66 Walker-Smith JA: Diarrhoeal disease: current concepts and future challenges. Malnutrition and infection. Trans R Soc Trop Med Hyg 1993;87(suppl 3):13-15.

7 Goulet O, Révillon Y, Jan D, et al: Neonatal short bowel syndrome. J Pediatr 1991;119:18 23.

-8 Goulet O, Ruemmele F, Lacaille F, Colomb V: Irreversible intestinal failure. J Pediatr Gastroenterol Nutr 2004;38:250-269.

$\checkmark 9$ Cuenod B, Brousse N, Goulet O, et al: Classification of intractable diarrhea in infancy using clinical and immunohistological criteria. Gastroenterology 1990;99:1037-1043.

10 Goulet O, Brousse N, Canioni D, et al: Syndrome of intractable diarrhoea with persistent villous atrophy in early childhood: A clinicopathological survey of 47 cases. J Pediatr Gastroenterol Nutr 1998;26:151-161.

11 Goulet O, Kedinger M, Brousse N, et al: Intractable diarrhea of infancy: a new entity with epithelial and basement membrane abnormalities. J Pediatr 1995;127:212-219.

12 Giraut D, Goulet O, Ledeist F, et al: Intractable diarrhea syndrome associated with phenotypic abnormalities and immune deficiency. J Pediatr 1994;125:36-42.
13 Davidson GP, Cutz E, Hamilton JR, Gall DG: Familial enteropathy: a syndrome of protracted diarrhea from birth, failure to thrive, and hypoplastic villous atrophy. Gastroenterology 1978;75:783-790.

14 Phillips AD, Schmitz J: Familial microvillous atrophy: A clinicopathological survey of 23 cases. J Pediatr Gastroenterol Nutr 1992;14: 380-396.

15 Holmberg C: Congenital chloride diarrhea. Clin Gastroenterol 1980;3:583-602.

$\checkmark 16$ Booth IW, Stange G, Murer H, Fenton TR, Milla PJ: Defective jejunal brush-border $\mathrm{Na}+$, $\mathrm{H}+$ exchange: a cause of congenital secretory diarrhoea. Lancet 1985; i:1066-1069.

17 Phillips AD, Jenkins P, Raafat F, WalkerSmith JA: Congenital microvillous atrophy: specific diagnostic features. Arch Dis Child 1985;60:135-140.

18 Phillips AD, Szfranski M, Man L-Y, Wall W: Periodic acid Schiff staining abnormality in microvillous atrophy: photometric and ultrastructural studies. J Pediatr Gastroenterol Nutr 2000;30:34-42. 
19 Phillips A, Fransen J, Hauri HP, Sterchi E: The constitutive exocytotic pathway in microvillous atrophy. J Pediatr Gastroenterol Nutr 1993;17:239-246.

20 Groisman GM, Amar M, Livne E: CD10: A valuable tool for the light microscopic diagnosis of microvillous inclusion disease (familial microvillous atrophy). Am J Surg Pathol 2002; 26:902-907.

21 Youssef N, Canioni D, Ruemmele F, et al: CD10 expression in microvillous inclusion disease (abstract). J Pediatr Gastroenterol Nutr 2003; 36:563.

-22 Raafat F, Green NJ, Nathavitharana KA, Booth IW: Intestinal microvillous dystrophy: a variant of microvillous inclusion disease or a new entity? Hum Pathol 1994;25:1243-1248.

-23 Phillips AD, Brown A, Hicks S, Schuller S, Murch SH, Walker-Smith JA, Swallow DM: Acetylated sialic acid residues and blood group antigens localise within the epithelium in microvillous atrophy indicating internal accumulation of the glycocalyx. Gut 2004;53:17641771.

24 Nathavitharana KA, Green NJ, Raafat F, Booth IW: Siblings with microvillous inclusion disease. Arch Dis Child 1994;71:71-73.

-25 Heinz-Erian P, Schmidt H, Le Merrer M, et al: Congenital microvillous atrophy in a girl with autosomal dominant hypochondroplasia. J Pediatr Gastroenterol Nutr 1999;28:203-205.

-26 Oliva MM, Perman JA, Saavedra JM, et al: Successful intestinal transplantation for microvillous inclusion disease. Gastroenterology 1994; 106:771-774.

27 Herzog D, Atkinson P, Grant D, et al: Combined bowel-liver transplantation in an infant with microvillous inclusion disease. J Pediatr Gastroenterol Nutr 1996;22:405-408.

28 Randak C, Langnas AN, Kaufman SS, et al: Pretransplant management and small bowelliver transplantation in an infant with microvillous inclusion disease. J Pediatr Gastroenterol Nutr 1998;27:333-337.

29 Ruemmele FM, Jan D, Lacaille F, et al: New perspectives for children with microvillous inclusion disease: early small bowel transplantation. Transplantation 2004;77:1024-1028.

- 30 Croft NM, Howatson AG, Ling SC, et al: Microvillous inclusion disease: an evolving condition. J Pediatr Gastroenterol Nutr 2000;31: 185-189.

- 31 Reifen RM, Cutz E, Griffiths AM, Ngan BY, Sherman PM: Tufting enteropathy: a newly recognized clinicopathological entity associated with refractory diarrhea in infants. J Pediatr Gastroenterol Nutr 1994;18:379-385.

- 32 Patey N, Scoazec JY, Cuenod-Jabri B, et al: Distribution of cell adhesion molecules in infants with intestinal epithelial dysplasia (tufting enteropathy). Gastroenterology 1997;113: 833-843.

- 33 Murch S, Graham A, Vermault A, et al: Functionally significant secondary inflammation occurs in a primary epithelial enteropathy. J Pediatr Gastroenterol Nutr 1997;24:467.
34 Krantz M, Jansson U, Rectors S, Ryd W, Kristiansson B: Hereditary intractable diarrhea with choanal atresia. A new familial syndrome. J Pediatr Gastroenterol Nutr 1997;24:470.

35 Abely M, Fromont Hankard G, et al: Intractable infant diarrhea with epithelial dysplasia associated with polymalformation. J Pediatr Gastroenterol Nutr 1998;27:348-352.

36 Djeddi D, Verkarre V, Talbotec C, et al: Tufting enteropathy and associated disorders (abstract). J Pediatr Gastroenterol Nutr 2002;34: 446.

37 Lachaux A, Bouvier R, Loras I, et al: Isolated deficient $\alpha 6 \beta 4$ integrin expression in the gut associated with intractable diarrhoea. J Pediatr Gastroenterol Nutr 1999;29:395-401.

38 Simon-Assmann P, Kedinger M: Heterotypic cellular cooperation in gut morphogenesis and differentiation. Cell Biol 1993;4:221-230.

39 Ayn NG, Waring P, Ristevski S, et al: Inactivation of the transcription factor Elf3 in mice results in dysmorphogenesis and altered differentiation of intestinal epithelium. Gastroenterology 2002; 122:1455-1466.

40 Cameron DJS, Barnes GL: Successful pregnancy outcome in tufting enteropathy. J Pediatr Gastroenterol Nutr 2003;36:158.

41 Lacaille F, Cuenod B, Colomb V, et al: Successful combined liver and small bowel transplantation in a child with epithelial dysplasia. J Pediatr Gastroenterol Nutr 1998;27:230-233.

42 Paramesh AS, Fishbein T, Tschernia A, et al: Isolated small bowel transplantation for tufting enteropathy. J Pediatr Gastroenterol Nutr 2003;36:138-140.

43 Itin PH, Pittelkow MR: Trichothiodystrophy: review of sulfur-deficient brittle hair syndromes and association with the ectodermal dysplasia. J Am Acad Dermatol 1990;22:705717.

44 Verloes A, Lombet J, Lambert Y, et al: Trichohepato-enteric syndrome: further delineation of a distinct syndrome with neonatal hemochromatosis phenotype, intractable diarrhea, and hair anomalies. Am J Med Genet 1997;68: 391-395.

45 Shulman RJ, Phillips S: Parenteral nutrition in infants and children. J Pediatr Gastroenterol Nutr 2003;36:587-607.

46 Colomb V, Fabeiro M, Dabbas M, Goulet O, Merckx J, Ricour C: Central venous catheterrelated infections in children on long-term home parenteral nutrition: incidence and risk factors. Clin Nutr 2000;19:355-359.

47 Colomb V, Goulet O, Rambaud C, et al: Long term parenteral nutrition in children: liver and gallbladder disease. Transplant Proc 1992;24: 1054-1055.

48 Moss RL, Das JB, Raffensperger JG: Total parenteral nutrition-associated cholestasis: clinical and histopathological correlation. J Pediatr Surg 1993;28:1270-1275.

49 Forchielli ML, Walker WA: Nutritional factors contributing to the development of cholestasis during total parenteral nutrition. Dev Pediatr 2003;50:245-267.
50 Colomb V, Jobert-Giraud A, Lacaille F, Goulet O, Fournet JC, Ricour C: Role of lipid emulsions in cholestasis associated with long-term parenteral nutrition in children. J Parenter Enteral Nutr 2000;24:345-350.

-51 Moseley RH: Sepsis-associated cholestasis. Gastroenterology 1997;112:302-305.

52 Lienhardt A, Rakotoambinina B, Colomb V, et al: Insulin secretion and sensitivity in children on cyclic total parenteral nutrition. J Parenter Enteral Nutr 1998;22:382-386.

$>53$ Belli DC, Fournier LA, Lepage G, et al: Total parenteral nutrition-associated cholestasis in rats: comparison of different amino acid mixtures. J Parenter Enteral Nutr 1987;11:6773.

54 Goulet O, de Potter S, Antebi H, et al: Longterm efficacy and safety of a new olive oil-based intravenous fat emulsion in pediatric patients: a double-blind randomized study. Am J Clin Nutr 1999; 70:338-345.

55 Clayton PT, Whitfield P, Iyer K: The role of phytosterols in the pathogenesis of liver complications of pediatric parenteral nutrition. Nutrition 1998;14:158-164.

56 Popinska K, Kierkus J, Lyszkowska M, et al: Aluminum contamination of parenteral nutrition additives, amino acid solutions, and lipid emulsions. Nutrition 1999;15:683-686.

57 Ben Hariz M, Goulet O, De Potter S, et al: Iron overload in children receiving prolonged parenteral nutrition. J Pediatr 1993;123:238241.

58 Moukarzel A, Song MK, Buchman AL, et al: Excessive chromium intake in children receiving total parenteral nutrition. Lancet 1992; 339:385-388.

59 Ling PR, Sheikh M, Boyce P, et al: Cholecystokinin (CCK) secretion in patients with severe short bowel syndrome (SSBS). Dig Dis Sci 2001;46:859-864.

60 Capron JP, Gineston JL, Herve MA: Metronidazole in prevention of cholestasis associated with total parenteral nutrition. Lancet 1983;i:446-447.

-61 Heubi JE, Wiechmann DA, Creutzinger V, et al: Tauroursodeoxycholic acid (TUDCA) in the prevention of total parenteral nutrition-associated liver disease. J Pediatr 2002; 141:237242.

62 Bresson JL, Narcy P, Putet G, et al: Energy substrate utilization in infants receiving total parenteral nutrition with different glucose to fat ratios. Pediatr Res 1989;25:645-648.

63 Kaufman SS: Prevention of parenteral nutrition-associated liver disease in children. Pediatr Transplant 2002;6:37-42.

64 MacFie J: Cyclic parenteral nutrition. Nutrition 1997;13:46-48.

65 Advenier E, Landry C, Colomb V, et al: Aluminum contamination of parenteral nutrition and aluminum loading in children on longterm parenteral nutrition. J Pediatr Gastroenterol Nutr 2003;36:448-453.

66 Colomb V, Goulet O, Ricour C: Home enteral and parenteral nutrition: Baillieres Clin Gastroenterol 1998;122:877-894. 
67 Scolapio JS: A review of the trends in the use of enteral and parenteral nutrition support. $\mathrm{J}$ Clin Gastroenterol 2004;38:403-407.

-68 Kaufman S, Atkinson JB, Bianchi A, Goulet O, Grant D, Langnas A, et al: Indications for pediatric intestinal transplantation: A position paper of the American Society of Transplantation. Pediatr Transplant 2001;5:80-87.

-69 Colomb V, Jobert-Giraud A, Lacaille F, Goulet O, Fournet JC, Ricour C: Role of lipid emulsions in cholestasis associated with long-term parenteral nutrition in children. JPEN J Parenter Enteral Nutr 2000;24:345-350.

-70 Iyer K, Horslen S, Torres C, et al: Histology is not predictive of functional liver recovery in parenteral-nutrition associated liver dysfunction (abstract). Pediatr Transplant 2003;7:69.

71 Bueno J, Ohwada S, Kocoshis S, et al: Factors impacting the survival of children with intestinal failure referred for intestinal transplantation. J Pediatr Surg 1999;34:27-33.
72 Fryer J, Pellar S, Ormond D, Koffron A, Abecassis M: Mortality in candidates waiting for combined liver-intestine transplants exceeds that for other candidates waiting for liver transplants. Liver Transplant 2003;9:748753.

73 Grant D, Abu-Elmagd K, Reyes J, Tzakis A, Langnas A, Fishbein T, Goulet O: Farmer D, on the behalf of the Intestine Transplant Registry: 2003 report of the intestine transplant registry: a new era has dawned. Ann Surg 2005; 241:607-613.

74 Beath SV, Booth IW, Murphy MS, et al: Nutritional care and candidates for small bowel transplantation. Arch Dis Child 1995;73:348350.
75 Fishbein TM, Schiano T, LeLeiko N, et al: An integrated approach to intestinal failure. Results of a new program with total parenteral nutrition, bowel rehabilitation, and transplantation. J Gastrointest Surg 2002;6:554-562.

76 Guarino A, De Marco G, Italian National Network for Pediatric Intestinal Failure: Natural history of intestinal failure, investigated through a national network-based approach. J Pediatr Gastroenterol Nutr 2003;37:136141.

77 Kocoshis SA, Beath S, Booth IW, Oliva GA, Goulet O, Kaufman SS, Lai HS, Luque C, Ohtsuka Y: Intestinal failure and small bowel transplantation, including clinical nutrition: Working Group report of the second World Congress of Pediatric Gastroenterology, Hepatology and Nutrition. J Pediatr Gastroenterol Nutr 2004;39(suppl 2):S655-S661. 